\title{
De ciertos ejercicios poscríticos cinematográficos. Estudio semántico discursivo
}

\section{Of certain postcritical cinematographic exercises. A semantic discursive study}

\author{
Yamila Cobos Castillo (D) Teresita Urra Vargas \\ Universidad de la Habana, La Habana, Cuba. \\ yamila.cobos@fenhi.uh.cu \\ Universidad de la Habana, La Habana, Cuba. \\ teresita.urra@flex.uh.cu
}

Gacceso abierto / open access

Cita: Cobos Castillo, Yamila y Urra Vargas, Teresita (2020). De ciertos ejercicios poscríticos cinematográficos. Estudio semántico discursivo. Textos en Proceso, 6(1), pp. 55-65. https://doi.org/10.17710/tep.2020.6. 1.3 cobosurra

Editores: Esperanza Alcaide Lara, Universidad de Sevilla, Ana Pano Alamán, Università di Bologna

Recibido: 21-01-2020

Aceptado: 23-05-2020

Conflicto de intereses: Las autoras han declarado que no poseen conflicto de intereses.

Copyright: @ Y Yamila Cobos Castillo, Teresita Urra Vargas. Esta obra está bajo licencia Creative Commons Reconocimiento 4.0.

\section{Resumen}

El trabajo se propone ofrecer una caracterización semántico-modal e ilocutiva del sujeto valorador Rufo Caballero en dos de sus llamados ejercicios poscríticos: Cinco veces dos: Historia descorazonadora en cinco actos y Dos amigos que se quieren. Se ha empleado como metodología fundamental el análisis dimensional para estudiar el contenido del significado valorativo de los enunciados seleccionados, partiendo de los fundamentos teóricos del Grupo de Estudios Semánticos y Análisis del Discurso de la Facultad de Lenguas Extranjeras (FLEX) en la Universidad de La Habana (UH). Además, se ha tenido en cuenta para complementar el estudio, en general, el análisis de algunas estructuras discursivas desde el enfoque del análisis crítico del discurso y los estudios sobre la transtextualidad desarrollados por G. Genette. Seguidamente se ofrecen los resultados del análisis que demuestran las particularidades estético-ideológicas y discursivas del sujeto enunciador.

Palabras clave: discurso, transtextualidad, categorías semánticas modales, ideología, pragmática.

\begin{abstract}
The work proposes to offer a semantic-modal characterization of the enunciating subject in cinematographic criticism Five times two: Disheartening history in five acts and Two friends who love Rufo Caballero. The dimensional analysis has been used as a fundamental methodology to study the content of the value meaning of the selected sentences, based on the theoretical foundations of the Group of Semantic Studies and Speech Analysis of the FLEX in the UH. In addition, it has
\end{abstract}


been taken into account to complement the study in general, the analysis of some discursive structures from the perspective of the critical discourse analysis and the transtextuality studies developed by G. Genette. Below are the results of the analysis that demonstrate the aesthetic-ideological and discursive particularities of Rufo Caballero in two of his so-called post-critical exercises.

Keywords: discourse, transtextuality, modal semantic categories, ideology, pragmatics.

\section{Introducción}

Con el arribo de la posmodernidad, todas las manifestaciones artísticas, así también la crítica cinematográfica, se lanzan a ensayar nuevos rumbos. Nace entonces la poscrítica como "hija legítima de la posmodernidad" (Padrón en González Machado, 2013, p. 39), como una manera de hacer, como un episteme, una sensibilidad artístico-literaria. Prolifera en Europa, sobre todo en Inglaterra y en América, fundamentalmente en Estados Unidos, en una época postindustrial, postestructural.

Refiere R. Barthes, en relación con estas ideas, que la verdadera crítica de las instituciones y de los lenguajes debía ser reconceptualizada. No debe conformarse en juzgarlos, sino en distinguirlos, en separarlos, en desdoblarlos. Para ser subversiva la crítica no necesita juzgar (1972, p. 14)

Seguidor de los nuevos enfoques críticos de R. Barthes (1972 y 1997), J. Kristeva (1978 y 1987), J. Derrida (1972 y 1989), entre otros teóricos, R. Caballero manifiesta un modo distinto de sensibilidad interpretativa y escritural, pues convierte su quehacer crítico en una obra de creación y se pronuncia como sujeto independiente y autosuficiente con libertad estilística de expresión.

Al respecto, González Machado (2013) comenta algunas diferencias metodológicas que manifiesta la crítica tradicional frente a la poscrítica, pues si la primera aboga por un lenguaje refuncionalizado, la segunda se vuelca hacia un metalenguaje, en el que la deconstrucción desempeña un papel prominente. Si antes la crítica tenía como principal objeto el estudio de la obra, ahora tiende a revelar mucho más la subjetividad del propio crítico, concebido este como un creador y no ya como un mero intérprete. La obra deja de ser un objeto acabado, un producto para convertirse en una exploración que es reconstruida por el crítico y no reproducida.

Debemos considerar entonces que el texto poscrítico pudiera entenderse como una obra de ficción más (un cuento, un poema, una obra de teatro o una mezcla de todos ellos). Tomemos como ejemplo, dos de los llamados ejercicios poscríticos, creaciones que el propio R. Caballero denominase e incluyese en su libro Nadie es perfecto (2010) y que hemos añadido al corpus de nuestra investigación.

El objetivo del siguiente trabajo es caracterizar las dimensiones ilocutiva y modal del sujeto enunciador de los textos críticos Cinco veces dos: Historia descorazonadora en cinco actos (I) (Caballero, 2010, pp. 85-88) y Dos amigos que se quieren (II) (Caballero, 2010, pp. 89-99). Además, atenderemos el análisis de algunos recursos estilísticos, estructuras y estrategias discursivas tomando como punto de partida la relación transtextual, y desde el componente ideológico del análisis crítico del discurso. 


\section{De transtextualidad en el texto poscrítico}

Por la perspectiva crítica que tiene, la transtextualidad o la transcendencia textual del texto (Genette, 1989, p. 9) se convierte en un recurso muy usual dentro de la posmodernidad artístico-literaria.

Nos ajustaremos a la definición y clasificación que ofrece G. Genette en su Palimpsestos sobre transtextualidad. En su primer acercamiento a dicho tema la concibe como "todo lo que pone al texto en relación manifiesta o secreta, con otros textos" (1989, pp. 9-10). Para ello presenta cinco tipos de relaciones transtextuales: la intertextualidad, la paratextualidad, la metatextualidad, la hipertextualidad y la architextualidad. Todas ellas han sido empleadas audazmente en los textos de opinión objeto de estudio, pero solo dos serán motivo de nuestra atención en el siguiente trabajo. Tal es el caso, por ejemplo, de la metatextualidad, la cual es definida como: "la relación, generalmente denominada «comentario», que une un texto a otro texto que habla de él sin citarlo (convocarlo), e incluso en el límite, sin nombrarlo (...). Es por excelencia la relación crítica" (Genette, 1989, p. 13).

Ampliando esta concepción con un enfoque más literario, González Hernández (2017, p. 43) acentúa además la inserción en la obra literaria de reflexiones o críticas acerca de los procesos de la escritura o de emisor-recepción de la obra literaria, lo cual le otorga un valor autorreferencial.

Cinco veces dos ( $5 \times 2$ 2): Historia descorazonadora en cinco actos (Caballero, 2010, pp. 85-88) es un comentario crítico a la película cuasi homónima del destacado director de cine francés François Ozon, nominada al León de Oro de Venecia en el 2004. Narrada en orden cronológico inverso, retrata la relación de una pareja poco convencional en cinco momentos relevantes de sus vidas.

La relación metatextual es uno de los recursos discursivos empleado por el agente crítico en este texto. Nótese, por ejemplo, en el enunciado siguiente:

1) (I) Con su brutal retrospección (más artificial en aquella Irreversible de Gaspar Noé), el director demuestra, además, que la única manera de resultar ingenioso con la narración no es la desdramatización o el rebajamiento de lo narrativo, recurso que puede parecer un rápido facilísimo (¿han escuchado directores de La clase, La niña santa o Línea de pase?); que hay miles de maneras de jugar con la narración y la estructura sin tener que prescindir necesariamente de ellas, en el contexto receptivo de un arte dramático por naturaleza (Caballero, 2010, p. 87)

En efecto, emplea como parámetro comparativo la retrospección para relacionar, a modo de comentario, el uso de este recurso narrativo en los filmes Cinco veces dos [5] e Irreversible [2]. El agente crítico jerarquiza en grado de superioridad al primero. Después, la interacción crítica se establece a partir del común denominador: modo de concebir los directores la dramatización y la narración en las películas: La clase [6], de la francesa Laurent Cantet, La niña santa [8], de la argentina Lucrecia Martel, y Línea de pase [1], del brasileño Walter Salles. En comparación con estos últimos filmes, el comentario entre textos cinematográficos expresado por Caballero resalta la ingeniosidad superior de François Ozon en Cinco veces dos.

La hipertextualidad, entendida por G. Genette (1989, p. 14) como una relación de imitación que une un texto $\mathrm{B}$ (hipertexto) a un texto anterior $\mathrm{A}$ (hipotexto), es otro de los procedimientos compositivos empleados por R. Caballero, pero esta vez en Dos amigos que se quieren (Caballero, 2010, pp. 8999), virtuoso hipertexto que nos permite disfrutar un enjundioso homenaje al 
diálogo de Gilbert y Ernest perteneciente a El crítico como artista, escrito en 1890 por Oscar Wilde, hipotexto de dicha crítica.

El crítico de cine imita y transforma a la vez el hipotexto de Wilde. La relación de imitación viene dada a partir del uso del diálogo como género literario y los nombres españolizados de los personajes, así como las formas de tratamiento refinado entre ellos. Tómense como ejemplos en el texto: mi estimado, dilecto, querido, etc. Al mismo tiempo transforma o transpone diegéticamente, siguiendo el criterio de Genette, la situación histórica comunicativa. La sociedad inglesa de fines de siglo XIX se convierte ahora en la sociedad intelectual habanera del siglo XXI. Los personajes de Dos amigos que se quieren debaten de forma mordaz sobre los filmes presentados recientemente en uno de los Festivales de Cine Francés de La Habana. Por supuesto, también ha cambiado el idioma: el español, en su variedad cubana de la lengua.

\section{El análisis crítico del discurso en relación con las modalidades semánticas}

Otro de los aspectos que pretendemos abordar es el análisis crítico del discurso teniendo en cuenta el punto de vista ideológico y la relación que manifiestan las ideologías en la interacción con las categorías semánticas modales. La posición que asumimos en relación con las definiciones de ideología y modalidad semántica, se adjudica a los preceptos teóricos de Van Dijk (1980, 1997, 1999, 2005 y 2008) y la teoría de las modalidades semánticas desarrollada por el Grupo de estudios semánticos y Análisis de discurso de la FLEX en la UH: Caballero Díaz (1989, 1996, 2002 y 2014), Caballero y Curbeira (2003), Galbán Pozo (2003), Ayala (2004), Curbeira y Urra (2012), Losada (2003, 2011 y 2015), entre otros.

Demostraremos nuestra concepción a partir de un análisis crítico del discurso en algunos enunciados pertenecientes a estos textos cinematográficos, en el que interactúan mayoritariamente las categorías semánticas modales de la valoración, la expresividad y el interés con las ideologías manifiestas en los enunciados seleccionados.

Van Dijk define ideología como "forma de conocimiento social y como la base de las representaciones sociales compartidas por los miembros de un grupo" (1999:23). En este sentido, pero asumiendo además la relación con el aspecto valorativo que nos interesa, Curbeira especifica que "son esencialmente, sistemas de cognición social valorados", pues en la configuración noética de las representaciones sociales está presente el establecimiento de los valores y su influencia en las maneras de modalizar las emisiones de discurso.

Es esta razón la que permite al hablante establecer:

juicios sobre qué está bien o mal (aspecto axiológico modal de las valoraciones apreciativas); sobre qué es correcto o incorrecto (evaluación normativa simple); sobre qué posición ocupa el referente valorado en la escala de valores establecida (jerarquización). De esta manera, la valoración, una de las categorías semánticas modales a las que haremos referencia, interactúa en la configuración de la estrategia discursiva con las posiciones ideológicas que se manifiestan en el discurso. (Curbeira, 2017, p. 3).

Ahora bien, los grupos sociales o individuos de acuerdo con sus intenciones en la interacción social pueden escoger los valores que serán proyectados en el discurso a través de las modalidades semánticas para garantizar la efectividad de este. Tales valores socioculturales, como la igualdad de género, la tolerancia, la 
aceptación de la diversidad en sus múltiples esferas, entre muchos otros, cimientan las ideologías.

Los miembros del Grupo de Estudios Semánticos y Análisis del Discurso de la FLEX de la UH consideramos entonces la ideología con un enfoque más abarcador, capaz de incluir todos los sistemas de representaciones sociales, también los políticos y no exclusivamente estos.

En relación con la modalidad semántica, se ajusta a nuestro trabajo la definición siguiente:

la categoría semántico-funcional caracterizada por el uso de medios lingüísticos de los diferentes niveles de la lengua para expresar contenidos interactivos (ilocutivos, perlocutivos), subjetivo-psicológicos (axiológicos y atributivos) y referenciales que reflejan las relaciones del emisor hacia lo que dice y del receptor hacia lo que recibe (Curbeira, 2017, p. 4)

Dicha modalidad semántica se subdivide en seis macrocategorías semánticas modales: la certidumbre, el interés, la afectividad, la lealtad, la expresividad y la valoración. Estas fueron esbozadas para su caracterización por Caballero Díaz (2002, pp. 137-160) y luego definidas, analizadas y caracterizadas por Galbán Pozo de la siguiente manera:

Valoración: categoría semántica modal que expresa la posición subjetiva e intencional ante lo dicho sobre la base de normas sociales en que se toma en cuenta el valor pragmático de los objetos y fenómenos que clasifican en una escala de valores axiológicos o paramétricos (Galbán Pozo, 2003, p. 118)

Afectividad: categoría semántica modal que expresa la posición subjetiva ante lo dicho sobre la base de los sentimientos afectivos que los objetos y fenómenos de la realidad despiertan en el sujeto. La misma se manifiesta en tres niveles de tensión discretizables a partir de los valores contrarios agrado - desagrado (tensión mínima), afecto-desafecto (tensión media) y amor-odio (tensión máxima) (Galbán Pozo, 2003, p. 120)

Certidumbre: categoría semántica modal que expresa la posición subjetiva ante lo dicho sobre la base de la seguridad como valor pragmático, que se traduce en la perspectiva cognoscitiva-discursiva como conocimiento seguro, claro y evidente de las cosas y en la perspectiva volitiva a partir de la firmeza o determinación como valor pragmático en que se sustenta el aspecto volitivo de las acciones del sujeto; la perspectiva volitiva como reflejo en la lengua de los procesos vinculados a la toma de decisiones para la realización de actividades encaminadas al logro de determinados fines. Dicha perspectiva gira alrededor de los contrarios decisión vs. indecisión, que reflejan el carácter de las actitudes (definidas vs. indefinidas o dudosas) de los individuos en relación con los comportamientos a asumir, en lo cual no se precisan contradictorios (Galbán Pozo, 2003, p. 20)

Interés: categoría semántica modal que expresa la posición subjetiva ante lo dicho poniendo de manifiesto cómo los objetos y fenómenos de la realidad provocan o no concentración de la atención, inclinación del ánimo hacia el objeto y/o constituyen un estímulo para la realización de un acto consciente se han discretizado a partir de la oposición de contrarios interés vs. obligación (que hemos denominado perspectiva volitivo-accional) se distingue una segunda perspectiva (perspectiva de la atención) a partir de la oposición de contrarios interés vs. desinterés (Galbán Pozo, 2003, p. 120)

Expresividad: categoría semántica modal que expresa la posición subjetiva ante lo dicho acerca de los objetos y fenómenos de la realidad poniendo de manifiesto el estado emocional del hablante ante estos en una doble perspectiva, a saber, la del modo de expresión caracterizada por la oposición de los contrarios desbordamiento 
-contención y la del tono emocional expresado, que refleja la oposición de los contrarios satisfacción-insatisfacción (Galbán Pozo, 2003, p. 120)

Lealtad: categoría semántica modal que expresa la posición subjetiva ante lo dicho en una triple perspectiva en tanto se vincula a los valores de sinceridad-insinceridad, buena intención-mala intención e ingenuidad-astucia, en dependencia del aspecto que se focaliza, a saber: la correspondencia del sentimiento y el discurso (perspectiva discursiva), el aspecto ético-intencional (perspectiva ético-intencional) o el aspecto cognoscitivo-intelectual (perspectiva cognoscitivo-intelectual), respectivamente (Galbán Pozo, 2003, p. 119).

Cobos Castillo (2018) expone esencialmente, en uno de sus artículos, la metodología científica desarrollada por el Grupo de Estudios Semánticos y Análisis del Discurso de la FLEX en la UH, la cual será retomada en nuestro trabajo en cuanto a la caracterización y descripción de las dimensiones ilocutiva y modal, las hipocategorías e infracategorías semánticas que permitirán la caracterización dimensional del sujeto valorador.

Establecida ya nuestra postura teórica realizaremos el análisis de la muestra correspondiente a algunos enunciados discursivos. Para ello referiremos en números romanos (I o II) el texto crítico aludido, luego, en números decimales enumeraremos los enunciados en cuestión. En el caso de los enunciados correspondientes al texto Dos amigos que se quieren (II), solo tomaremos para la muestra los relacionados con Gilberto, pues es quien manifiesta la postura crítica más enriquecedora.

\section{Descripción y análisis de la muestra}

En sus estudios, Van Dijk (2005) asegura que las ideologías son adquiridas, expresadas, promulgadas y reproducidas por el discurso, a través de varias estructuras y estrategias discursivas. Veamos el ejemplo a continuación:

2) (I) Con su brutal retrospección (más artificial en aquella Irreversible de Gaspar Noé), el director demuestra, además, que la única manera de resultar ingenioso con la narración no es la desdramatización o el rebajamiento de lo narrativo, recurso que puede parecer un rápido facilísimo (¿han escuchado directores de La clase, $\mathrm{La}$ niña santa o Línea de pase?); que hay miles de maneras de jugar con la narración y la estructura sin tener que prescindir necesariamente de ellas, en el contexto receptivo de un arte dramático por naturaleza (Caballero, 2010, p. 87)

El enunciado I.2 expresa desde la macrocategoría de la valoración una apreciación categórica realizada por el sujeto crítico de cine en los dominios estético y ético-moral. Desde una actitud modal aprobadora juzga el trabajo del realizador (objeto focalizado) en cuanto a su aceptación con respecto a la igualdad de géneros y la diversidad de orientaciones sexuales. Teniendo en cuenta la macrocategoría de la expresividad el tono emocional es de satisfacción acudiendo para ello a un modo desbordado. Apropiadamente acentúa dicho desbordamiento a partir del uso desprejuiciado y no peyorativo en el texto del anglicismo queer 'raro'. A través de su discurso, este agente crítico nos va develando claramente su ideología con respecto a la posición ética asumida en las disyuntivas: ser tolerante vs. no ser tolerante, ser equitativo vs. no ser equitativo.

3) (II) Los gringos construyen a la perfección sus historias, sólo que para decir lindezas. Los franceses hacen un cine muy maduro, que se ocupa de la vida con hondura, con valentía, sin fuegos de artificios ni pacotilla mediática, incluso con un vértigo cada vez mayor hacia la vida de la gente menos encumbrada, en franca 
vocación social; y en todo ello es cierto que pesan los siglos de cultura, cuando los gringos apenas tienen a Julia Roberts y la hamburguesa (Caballero, 2010, p. 91).

Partiendo de la macrocategoría de la valoración, el enunciado anterior manifiesta con transparencia la ideología estética del agente crítico: su preferencia rotunda por el cine francés. Estilísticamente, usa adjetivaciones cortantes tales como: sin fuegos de artificios ni pacotilla mediática, imágenes provocativas como: los gringos apenas tienen a Julia Roberts y la hamburguesa, para declarar su acto crítico drástico con respecto al cine norteamericano. El espíritu intolerante, descortés de Wilde ante lo que consideraba mediocre nos vuelve a sorprender, esta vez en el Gilberto de Rufo, quien no escatima desmanes para referirse a dos símbolos ineludibles de la cultura norteamericana. Semánticamente, estamos en presencia de una apreciación estética categórica del sujeto valorador en la que el cine francés es enaltecido. A partir de una oposición binaria, este es jerarquizado en grado superior teniendo en cuenta la madurez y calidad vertidas en la propensión de temáticas sociales y no meramente de entretenimiento. La posición ideológica del sujeto crítico refleja su libertad de opinión.

4) (I) Una preciosa película que, si incurre en algunos de los inevitables lugares comunes sobre la dificultad de vivir, de sostener las emociones, de comprender a los demás y de entender los dolorosos ciclos vitales, se salva por la delicadeza (Caballero, 2010, p. 85)

Correspondiente al dominio estético esta opinión focaliza la película. El enunciado expresa una valoración apreciativa ambivalente. Asume para ello una actitud modal de ponderador reflexivo reflejada a través de un tono más contenido a través del procedimiento de atenuación empleado para minimizar la cantidad: algunos..., pues la satisfacción estética que manifiesta el crítico es regular.

5) (I) $\mathrm{Al}$ tiempo, la actuación de Valeria Bruni Tedeschi hace comprender, dramáticamente, por qué Gilles está loco por Marion. Gilles y quien no es Gilles (Caballero, 2010, p. 86).

6) (I) La Marion de la Bruni-Tedeschi queda caracterizada como la típica mujer que podía perder para siempre a cualquiera, y la intérprete expresa la inteligencia y sensualidad de Marion con una fuerza magnética que la cámara agradece lo mismo que Gilles. Y de los espectadores ni se diga (Caballero, 2010, p. 86)

7) (I) Los recursos de la extraordinaria actriz no se agotan nunca: la película termina y Marion continúa en nuestra mente, jcómo no vamos a entender a Gilles!

(Caballero, 2010, p. 86).

Estos enunciados discursivos muestran valoraciones apreciativas categóricamente positivas con respecto a los personajes. En estrecha fusión con las valoraciones, la macrocategoría de interés se manifiesta desde la perspectiva de la atención. El empleo de frases lexicalizadas con cierto desenfado expresivo argumenta cómo la magistral actuación de dicha actriz hechiza a todo tipo de observadores.

La categoría semántica de expresividad está presente a través del tono de satisfacción y del estado de desbordamiento del sujeto enunciador. Nótese entonces que una de sus estrategias discursivas es introducir en su discurso crítico académico, construcciones lexicalizadas cortas y pícaras, intensas con doble sentido que caracterizan el registro coloquial de la variedad cubana de la lengua. Su objetivo es 
poder ser entendido por todo tipo de público correspondiente a diversos grupos sociales. Tómense como ejemplos: Gilles y quien no es Gilles / Y de los espectadores ni se diga / jcómo no vamos a entender a Gilles!

Es oportuno acotar que tal objetivo cumple, además, una función ideológica en su discurso, pues sus relaciones sociales de poder se afianzan mejor para ejercer como autoridad crítica si capta la mayor aceptación y preferencia de sus destinatarios.

8) (II) Ahora, en Los destinos sentimentales no hay ni forma ni pasión, sino una longaniza descriptiva, anémica y deslavazada, sin énfasis dramático alguno, con pésima dirección de actores y una dramaturgia muy irregular, que gira de enunciado cada media hora (Caballero, 2010, p. 91).

En este enunciado que alude al filme Los destinos sentimentales [3] del director Olivier Assayas, el actante ilocutivo modal realiza una apreciación categóricamente negativa del objeto focalizado que aparece intensificada mediante la enumeración. El sujeto valorador se caracteriza por presentar los siguientes atributos modales: apreciador, severo, seguro, desbordado en la adjetivación y sincero.

9) (II) Conocemos que la redundancia es el caballo de Troya del melodrama, pero una cosa supone la dosis razonable de brutalidad y otra, el morbo de la sobresaturación de pena de una película cancerosa a cada plano. El tumor no deja crecer al niño ni avanzar la película (Caballero, 2010, p. 93).

Al analizar la dimensión ilocutiva del enunciado anterior, cuyo referente es la crítica dirigida al largometraje de la directora de cine franco-islandesa Sólveig Anspach ;Haut les coeurs; o ;Arriba el ánimo! [7], consideramos que es un acto de apreciación estética problemática, axiológicamente negativo, en el que se manifiestan los siguientes atributos modales del sujeto valorador: flexible, irónico, sarcástico, desbordado en cuanto a la macrocategoría expresividad. Pues, utiliza una expresión metafórica "caballo de Troya", helenismo ya popularizado, para referir la entrada disimulada con segundos objetivos de este recurso en uno de los géneros cinematográficos más populares.

10) (II) El encanto y la calidad de Sergi pueden ser muy riesgosos para la dirección. Este tipo de actores, que de aparecer se roban el show, son dinamita. (Caballero, 2010:99)

Tomando como objeto focalizado el despampanante desempeño actoral de Sergi López en el filme Harry, un amigo que os quiere [4], dirigida por Dominik Moll, el sujeto crítico realiza una apreciación estética axiológicamente positiva en la que muestra atributos modales tales como: ponderador reflexivo, sincero, también satisfecho y desbordado en cuanto a la categoría expresividad e interesado en llamar la atención a los directores de cine en cuanto a la perspectiva volito-accional. Para ello emplea unidades fraseológicas coloquiales llamativas que van matizando su discurso, por ejemplo: robarse el show y ser dinamita. El agente crítico de cine se ha propuesto ser enormemente expresivo y desenfadado.

\section{Consideraciones finales}

Podemos considerar que estas críticas cinematográficas muestran la influencia del Posmodernismo en cuanto al empleo de ciertos recursos discursivos que lo 
caracterizaron. En estos textos de opinión hemos traído a colación la metatextualidad y la hipertextualidad.

Por otra parte, en el análisis de esta muestra se expresa la manifestación de las ideologías, particularmente las relacionadas con la posición ético-moral y estética del sujeto crítico como representante estético de un grupo social desprejuiciado, diverso, que ejerce la libertad de opinión, teniendo en cuenta la interpretación de las modalidades semánticas que caracterizan su discurso.

El sujeto enunciador crítico de cine se caracteriza por realizar valoraciones estéticas que discurren desde el eje positivo al negativo de la valoración, con predominio del voto positivo. Sus apreciaciones son complementadas sobremanera por las categorías semánticas de expresividad e interés hacia los objetos focalizados.

Rufo Caballero muestra su peculiar estilo de interpretar y escribir haciendo uso de diversos recursos y estrategias discursivas que le permiten transitar con deferencia y exaltación por los distintos registros de la lengua.

\section{Referencias}

1. Cobos Castillo, Y. (2018). Nadie es perfecto: un análisis semántico discursivo dimensional de la crítica cinematográfica de Rufo Caballero, Textos en Proceso, 4(1), pp. 30-46. DOI: https://doi.org/10.17710/tep.2018.4.1.2coboscastillo

2. Ayala, I. M. (2004). La caracterización del discurso de los personajes femeninos en cuentos de Alice Walker. (Tesis doctoral). Universidad de La Habana, La Habana.

3. Barthes, R. (1972). Critica y verdad. Buenos Aires: Siglo XXI. Recuperado de: http://bida.uclv.edu.cu/bitstream/handle/123456789/10315/Barthes,\% 20Roland\%20-\%20Cr\%C3\%ADtica\%20y\%20verdad.pdf?sequence=1

4. Barthes, R. (1997). El grado cero de la escritura. Seguido de nuevos ensayos críticos. México: Siglo XXI. Recuperado de: http://imago.yolasite.com/resources/ BARTHES,\%20El\%20grado\%20cero\%20de\%20la\%20escritura.pdf

5. Caballero Díaz, L. (1989). Introducción al estudio semántico e ideográfico de la valoración en el español en Cuba. Dos aproximaciones al español de Cuba. La Habana: EMPES.

6. Caballero Díaz, L. (1996). Ilocuciones Valorativas. El Verbo Español. En Wotjiak, G. (Coord.), El verbo español: aspectos morfosintácticos, sociolingüisticos y lexicogenéticos (pp. 93-100). Berlín/Madrid: Vervuert/Iberoamericana. DOI: https://doi.org/10.31819/9783865278326-007

7. Caballero Díaz, L. (2002). Modalidades semánticas del lenguaje. En Aleza Izquierdo, M. y Gregori Torada, N. (Coords.), Estudios lingüísticos cubanos (II). Homenaje a Leandro Caballero Díaz (pp. 137-160). Valencia: Universitat de València.

8. Caballero Díaz, L. (2014). Semántica y Diccionario. La Habana: Editorial Ciencias Sociales.

9. Caballero Díaz, L. y Curbeira, A. (2003). Las categorías semánticas de la modalidad. En Águila Muñiz, M. del (Ed.), Lecturas de Semántica (Vol. 1, pp. 117-125). La Habana: Editorial Félix Varela.

10. Caballero, R. (2010). Nadie es perfecto. Crítica de cine. La Habana: Editorial Arte y Literatura. Ediciones ICAIC. 
11. Curbeira Cancela, A. (2017). La interacción en el discurso de las ideologías y las categorías semánticas modales de lealtad y valoración. En X Conferencia Internacional Lingüística, 2017, La Habana, Cuba.

12. Curbeira Cancela, A. y Urra Vargas, T. (2012). Diccionario ideográfico y semántico de la valoración estética positiva en español. La Habana: Editorial UH.

13. Derrida, J. (1972). Dos ensayos. La estructura, el signo y el juego en el discurso de las ciencias humanas. El teatro de la crueldad y la clausura de la representación. Barcelona: Cuadernos Anagrama.

14. Derrida, J. (1989). La deconstrucción en las fronteras de la filosofía: la retirada de la metáfora. Barcelona: Paidós/Ice-UAB.

15. Palés, M. (Ed.) (2004). Diccionario español-inglés/english-spanish [versión electrónica]. Madrid: Espasa Calpe, S. A.

16. Dijk, T. A. van (1980/1996). Estructuras y funciones del discurso. Siglo Veintiuno Editores. Recuperado de:

http://mastor.cl/blog/wpcontent/uploads/2015/08/Libro-Teun-Avan-Dijk-Las-Estructuras-y-Funciones-del-Discurso.pdf

17. Dijk, T. A. van (1997). The Study of Discourse.Discourse as Structure and Process. London: SAGE. Recuperado de:

https://sk.sagepub.com/books/discourse-as-structure-and-process

18. Dijk, T. A. van (1999). Ideología. Una aproximación multidisciplinaria. Barcelona: Editorial Gedisa. Recuperado de:

https://sites.google.com/site/mindsamseakins/ideologia-unaaproximacion-multidisciplinaria-28922608

19. Dijk, T. A. van (2005). Ideología y análisis del discurso. Utopía y praxis latinoamericana, 10(29), abril-junio, pp. 9-36. Recuperado de: https://produccioncientificaluz.org/index.php/utopia/article/view/27 $\underline{03}$.

20. Dijk, T. A. van (2008). Semántica del discurso e ideología. Discurso y Sociedad, 2(1), pp. 201-261. Buenos Aires.

21. Galbán Pozo, A. M. (2003). Aproximación al estudio de las categorías semánticas modales (valoración, lealtad, certidumbre, interés, afectividad y expresividad) y su expresión a través de verbos de las lenguas españolas y alemanas. (Tesis doctoral). Universidad de La Habana, La Habana.

22. Genette, G. (1989). Palimpsestos. La literatura en segundo grado. Madrid: Taurus. Recuperado de:

https://www.academia.edu/10415500/Palimpsestos._Laliteratura_en segundo_grado.

23. González, H. M. (2017). La resemantización mítica en el discurso narrativo de una representación de Los Novísimos (1993-2003). (Tesis doctoral). Universidad de La Habana, La Habana.

24. González, Machado C. (2013). El riesgo de la herejía. Cartografía de la crítica y el discurso filmico en la revista Cine Cubano (1960-2010). La Habana: Ediciones ICAIC.

25. Kristeva, J. (1978/1981). La palabra, el diálogo y la novela. En Semiótica. Madrid: Fundamentos. Recuperado de: http://pdfhumanidades.com/sites/default/files/apuntes/ Julia\%20Kristeva\%20\%20La\%20Palabra\%2C\%20el\%20Di\%C3\%A1logo 


\section{\%20y\%20la\%20Novela.pdf}

26. Kristeva, J. (1987). El lenguaje ese desconocido. Introducción a la lingüistica. Madrid: Fundamentos. Recuperado de: https://introduccionlenguaje2010.files.wordpress.com.

27. Padrón, F. (2004). La profesión maldita. Editorial Oriente: Santiago de Cuba.

28. Wilde, O. (1890). La importancia de no hacer nada. (El crítico como artista I). Traducción: Lorenzo F. Díaz. Editor digital Titivillus. Recuperado de:

https://www.academia.edu/27750040/Oscar_Wilde_La_importancia _de_no_hacer_nada.

\section{Referencias a películas}

1. Andrade, M. y Salles, W. (2008). Línea de pase. Brasil: Videofilmes Produçoes Artisticas / Pathé Pictures International.

2. Cassel, V. y Noé, G (2002). Irreversible. Francia: Les Cinémas de la Zone / Studio Canal.

3. Jacques, F. y Assayas, O. (2000.) Los destinos sentimentales. Francia: Pathé.

4. Marchand, G. y Moll, D. (2000). Harry, un amigo que os quiere. Francia: Diaphana Distribution / M6 Films / Canal+ / M6 Films / CNC / La Sofica Sofinergie 5.

5. Missonnier, M. y Ozon, F. (2004). Cinco veces dos (5x2). Francia: Fidelité Films / Canalt.

6. Scotta, C. y Cantet, L. (2008). La clase (Entre les murs). Francia : Haut et Court.

7. Sobelman, P. y Anspach, S. (1999). jArriba el ánimo! (jHaut les coeurs!). Francia y Bélgica: Ex Nihilo Agat Films \& Cie / Entre Chien et Loup / Radio Télévision Belge Francophone.

8. Stantic, L. y Martel, L. (2004). La niña santa. Argentina: Lita Stantic. 